\title{
Thermal stability of carbon nanotubes, fullerene and graphite under spark plasma sintering
}

\author{
Faming Zhang ${ }^{\mathrm{a}, *}$, Carmen Mihoc ${ }^{\mathrm{a}}$, Furqan Ahmed ${ }^{\mathrm{b}, \mathrm{c}}$, Christian Lathe ${ }^{\mathrm{d}}$, Eberhard Burkel ${ }^{\mathrm{a}}$ \\ a Institute of Physics, University of Rostock, August Bebel Str. 55, Rostock 18055, Germany \\ ${ }^{\mathrm{b}}$ Department of Materials Science and Engineering, University of Erlangen-Nürnberg, Martens Str. 5, Erlangen 91058, Germany \\ c Department of Metallurgical and Materials Engineering, University of Engineering and Technology, Lahore, Pakistan \\ ${ }^{\mathrm{d}}$ Helmholtz Centre Potsdam, GFZ German Research Centre for Geosciences, Centre for $\mathrm{CO}_{2}$ Storage, Telegrafenberg, 14473 Potsdam, Germany
}

\section{A R T I C L E I N F O}

\section{Article history:}

Received 1 April 2011

In final form 8 May 2011

Available online 11 May 2011

\begin{abstract}
A B S T R A C T
The thermal stabilities of carbon nanotubes, fullerene and graphite were investigated under spark plasma sintering (SPS). Results were compared with data from synchrotron radiation in situ high temperature $\mathrm{X}$-ray diffraction of these materials. Part of the nanotubes and fullerene transformed into diamond under SPS, but graphite kept stable. There was no diamond conversion in the in situ X-ray diffraction experiments under the same condition. Their phase transitional mechanism indicated the presence of plasmas during the SPS operation.
\end{abstract}

(c) 2011 Elsevier B.V. All rights reserved.

\section{Introduction}

The carbon nanotubes, fullerene (C60) and graphite have broad applications as structural and functional materials. Therefore, it is of great importance for a better in-depth understanding of their thermal stability under severe physical conditions [1,2]. Spark plasma sintering (SPS), also defined as field assisted sintering technique (FAST) or pulsed electric current sintering (PECS), is an electric field assisted sintering process utilizing ON-OFF DC pulse energizing [3]. During its treatment, pulsed DC current directly passes through the graphite die, as well as the powder compact, in case of conductive samples [4]. During study of the thermal stability of multi-walled carbon nanotubes (MWCNTs) under various SPS conditions, it was found that under SPS conditions of $1500^{\circ} \mathrm{C}$ at very low pressure carbon nanotubes were unstable and transformed to diamonds without any catalysts being involved [5-7]. Recently, Inam et al. [8] reported that multiwall carbon nanotubes were not preserved for ceramic matrices that require high sintering temperatures $\left(>1600^{\circ} \mathrm{C}\right.$ ) and longer processing times $(>13 \mathrm{~min})$ in the SPS. We proposed that the spark plasmas may play a key role to provide most of the energy required in this diamond transition $[5,6]$. It indicates that the SPS has a potential to be used as an alternative method for diamond generation, and it also provides an indirect way to validate the existence of the plasmas during the SPS. However, at this point it needs further investigations due to the still on-going arguments about whether the spark plasmas actually occur during the SPS process $[9,10]$. In this study, we used an indirect way to prove the presence of plasmas during the SPS.

\footnotetext{
* Corresponding author. Fax: +493814986862.

E-mail address: faming.zhang@uni-rostock.de (F. Zhang).
}

The thermal stability and phase transitional behavior of carbon nanotubes, C60 and graphite were investigated under the SPS (pulsed DC field). The pure MWCNTs, C60 and graphite powders were processed by using the SPS. Their phase constitutions were investigated by using synchrotron radiation-high energy X-ray diffraction and Raman spectroscopy. For a comparison study, these carbon materials were also studied using the in situ high temperature (AC field) synchrotron radiation X-ray diffraction. Their phase transitional mechanisms under such novel sintering technique were discussed.

\section{Experimental}

The MWCNTs (10-20 nm) with purity above 95\% were obtained from Shenzhen Nanotech Port, Ltd., China. The C60 powders with purity of 99.5\% were obtained from SES Research, Huston, USA. The graphite powders with purity of $99.0 \%$ were purchased from Alfa Aesar, Germany.

These carbon powders were pressed into a graphite die for SPS treatment to form disk-shaped samples of $20 \mathrm{~mm}$ diameter and $5 \mathrm{~mm}$ thickness. The SPS experiments were conducted using a Model HPD-25/1 FCT spark plasma sintering system (FCT systeme $\mathrm{GmbH}$, Rauenstein, Germany), under an axial pressure of $80 \mathrm{MPa}$ in vacuum ( $<6 \mathrm{~Pa}$ ). A heating rate of $100 \mathrm{~K} / \mathrm{min}$ was adopted, and the sintering process lasted typically $20 \mathrm{~min}$. The applied direct current for SPS was about $1000 \mathrm{~A}$, with a pulse duration of $12 \mathrm{~ms}$ and an interval of $2 \mathrm{~ms}$.

The phase identification of the obtained carbon samples was performed using high-energy X-ray diffraction at beamline BW5 (DESY/HASYLAB Hamburger Synchrotron Laboratory) with a wavelength of $0.15339 \AA$ ( $80.828 \mathrm{keV})$. The carbon samples were also 

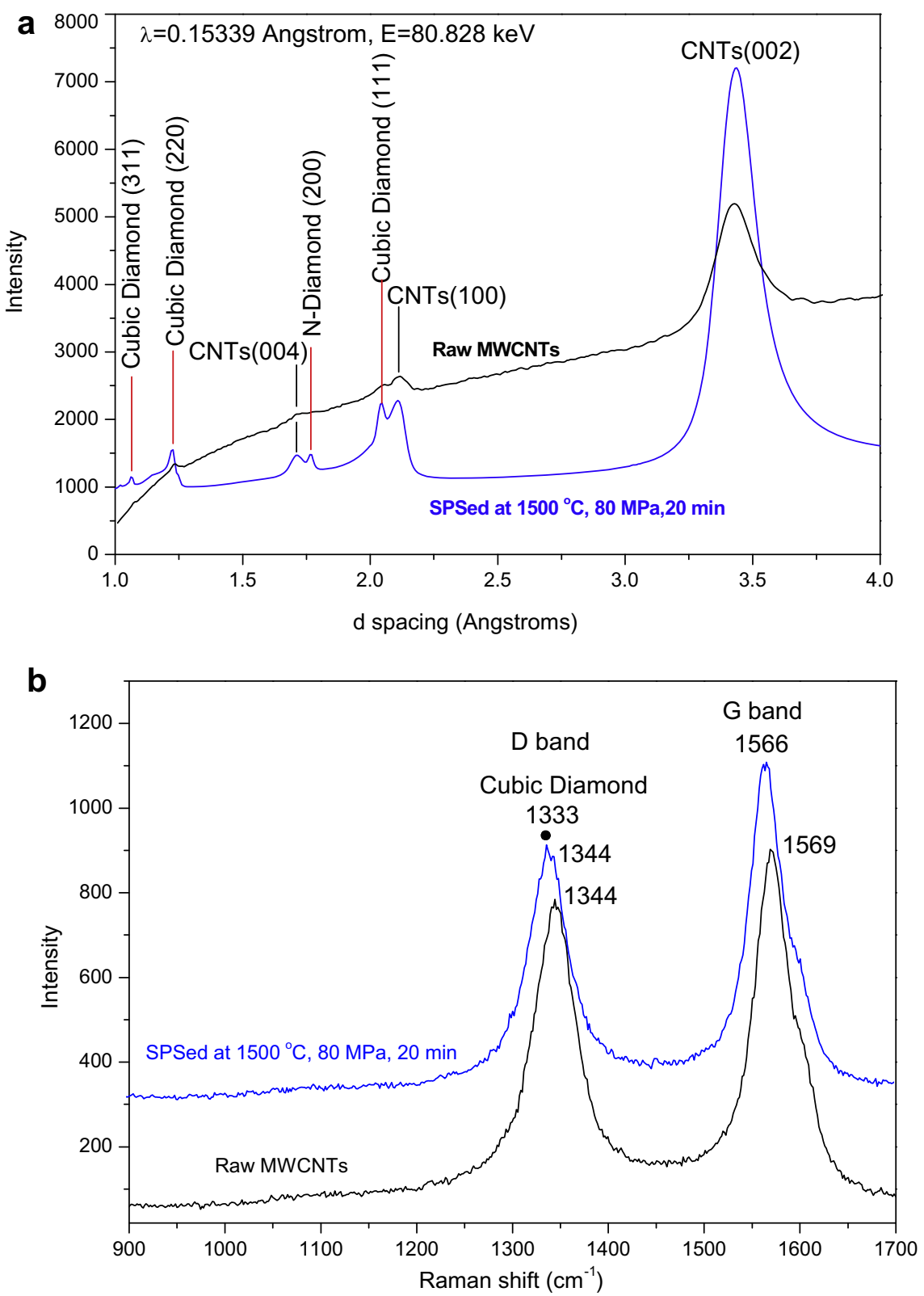

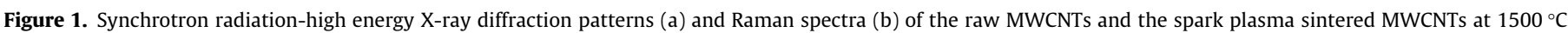
$80 \mathrm{MPa}$ for $20 \mathrm{~min}$.

analyzed by a Renishaw-2000 Laser Raman spectroscopy system with a He-Ne laser excited at $514 \mathrm{~nm}$. The stability of these carbon samples was investigated by the in situ high temperature X-ray diffraction at the MAX80/F2.1 high-pressure beamline of Helmholtz Centre Potsdam at HASYLAB/DESY. The MAX80 instrument uses a cubic-anvil-type press, which is known to provide better results for isotropic pressure generation compared to other multiple-anvil high-pressure devices [11]. The carbon samples were contained in cube cells made of a mixture of boron and epoxy resin with $4 \mathrm{~mm}$ edge length in a non-oxygen atmosphere. The pure MgO powder was used as a reference material in the cube cells. An in situ measurement comprises the room-temperature compression to the desired pressure, followed by isobaric constant-rate heating. X-ray diffraction patterns were acquired in energy-dispersive mode (EDX) during continuous specimen heating (up to $1500{ }^{\circ} \mathrm{C}$ ) under an applied pressure of $80 \mathrm{MPa}$. The EDX method re- lies on the use of a well-collimated and polychromatic (white) incident synchrotron radiation beam. The XRD patterns were collected each $10^{\circ} \mathrm{C}$ during constant heating.

\section{Results and discussion}

The pure MWCNTs were SPSed at $1500{ }^{\circ} \mathrm{C}$ under pressure of $80 \mathrm{MPa}$ for holding time of $20 \mathrm{~min}$. Figure 1a shows the synchrotron radiation-high energy X-ray diffraction patterns of the raw MWCNTs and the spark plasma sintered (SPSed) MWCNTs. The raw MWNCTs show a main diffraction peak at $3.43 \AA$ corresponding to the CNTs $\left(\begin{array}{lll}0 & 0 & 2\end{array}\right)$ plane spacing, and weak peaks at 2.10 and 1.70 A corresponding to the CNTs ( $\left.\begin{array}{lll}1 & 0 & 0\end{array}\right)$ and ( $\left.\begin{array}{lll}0 & 0 & 4\end{array}\right)$ plane spacing, respectively. After SPS processing, the MWCNTs diffraction peaks are still presented in the sintered MWCNTs compacts, but the 

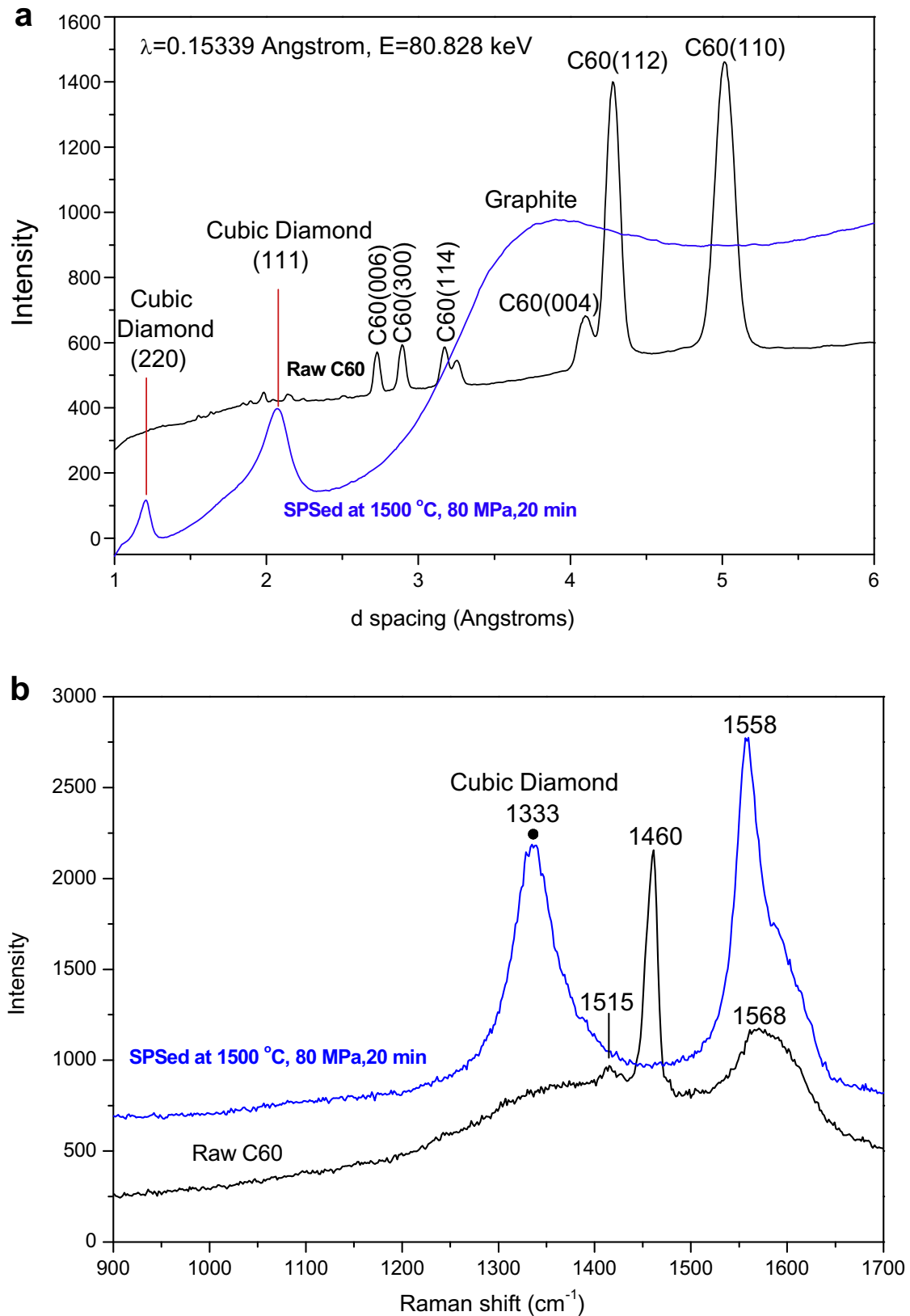

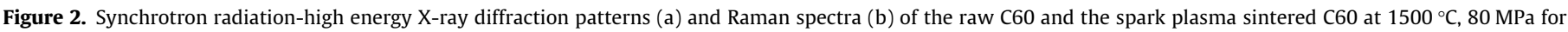
$20 \mathrm{~min}$.

peaks of the CNTs ( $\left.\begin{array}{lll}0 & 0 & 2\end{array}\right),\left(\begin{array}{lll}1 & 0 & 0\end{array}\right)$ and $\left(\begin{array}{lll}0 & 0 & 4\end{array}\right)$ are stronger than those in the raw MWCNTs. It indicates that the SPS process improved the crystallinity of the MWCNTs, which is consistent with the results of Yang et al. [12]. Additionally, new peaks were detected in the sample centered at 2.05, 1.23, 1.06 and 1.76 A corresponding to the cubic diamond (ICDD No. 65-537) (1 111 ), (2 200$),\left(\begin{array}{lll}3 & 1 & 1\end{array}\right)$ and $n$ diamond (ICDD No. 43-1104) (2 00 ) plane spacing, respectively. Figure 1b shows Raman spectra of the raw MWCNTs and the SPSed MWCNTs. The result of the raw MWCNTs show that their D band appeared at $1344 \mathrm{~cm}^{-1}$ and $\mathrm{G}$ band appeared at $1569 \mathrm{~cm}^{-1}$. After SPS processing, the D peak shifted to $1333 \mathrm{~cm}^{-1}$ corresponding to the cubic diamond but there was still a weak peak at $1344 \mathrm{~cm}^{-1}$ belonging to the un-reacted MWCNTs, the $G$ band shifted to $1566 \mathrm{~cm}^{-1}$ relating to the $\mathrm{sp}^{2}$ bonded carbon vibrations. The results of the X-ray diffraction and Raman spectroscopy confirmed the diamond formation in the MWCNTs sample after SPS at $1500{ }^{\circ} \mathrm{C}, 80 \mathrm{MPa}$ for $20 \mathrm{~min}$.

Figure 2a shows the synchrotron radiation-high energy X-ray diffraction patterns of raw $\mathrm{C} 60$ and the SPSed $\mathrm{C} 60$ at $1500{ }^{\circ} \mathrm{C}$, $80 \mathrm{MPa}$ for $20 \mathrm{~min}$. The raw $\mathrm{C} 60$ exhibits diffraction peaks at $\mathrm{d}$ spacing of $5.01,4.28,4.11,3.18,2.9,2.74 \AA$ belonging to C60 (1 110 ), (1 112 2), ( $\left.\begin{array}{lll}0 & 0 & 4\end{array}\right),\left(\begin{array}{lll}1 & 1 & 4\end{array}\right),\left(\begin{array}{lll}3 & 0 & 0\end{array}\right),\left(\begin{array}{lll}0 & 0 & 6\end{array}\right)$ planes (ICDD No. 470787), respectively. The C60 after SPS shows the cubic diamond diffraction peaks at d spacing of 2.06 and $1.23 \AA ̊$ and a broad graphite peak. The C60 diffraction peaks disappeared indicating the C60 has completely transformed into diamond and graphite phases after the SPS processing. Figure 2b shows the Raman spectra of the raw C60 and the SPSed C60. The raw C60 shows a sharp peak appeared at $1460 \mathrm{~cm}^{-1}$, and two weak, broad peaks centered at 1568 and $1515 \mathrm{~cm}^{-1}$. After SPS processing, it shows the cubic dia- 

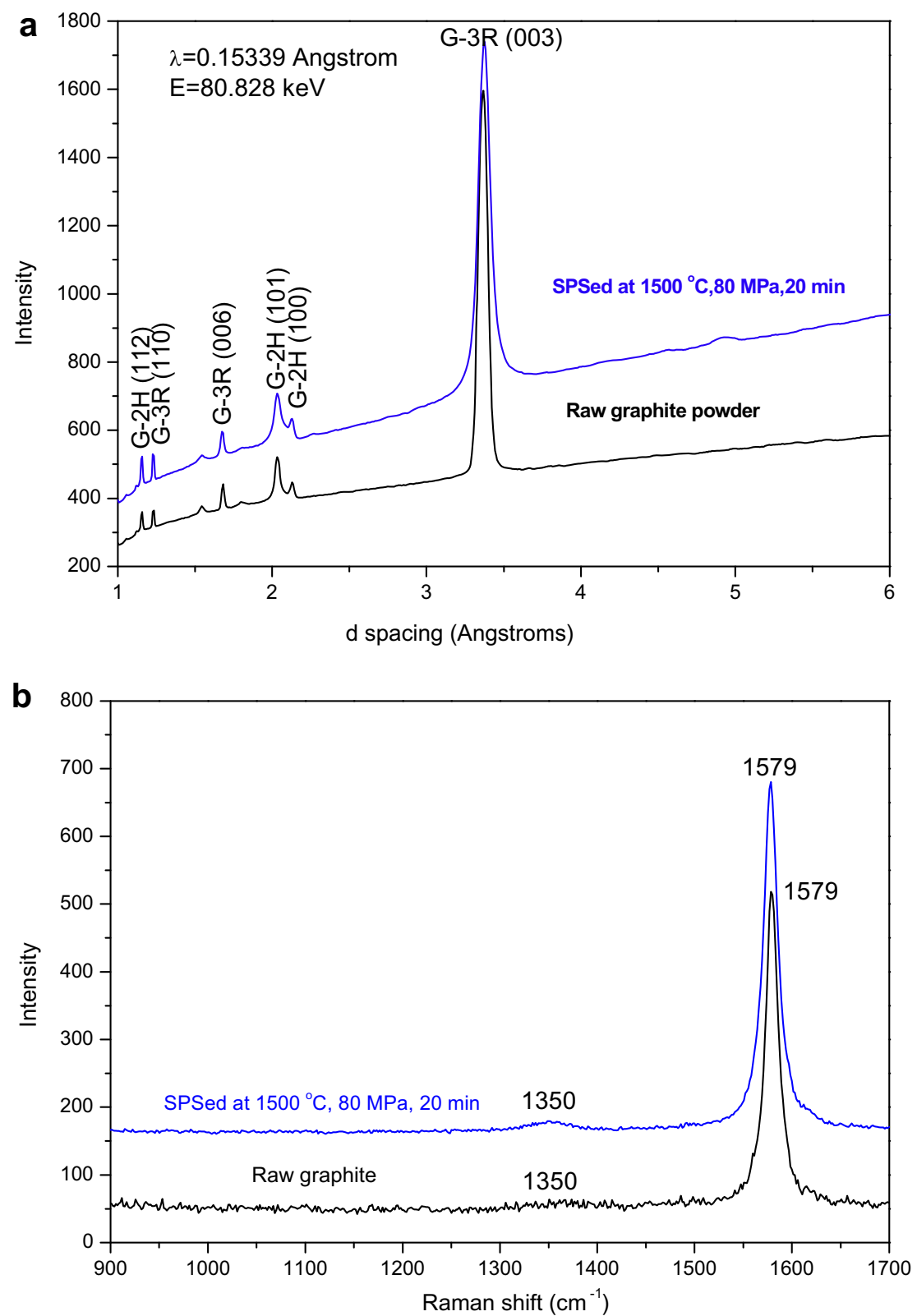

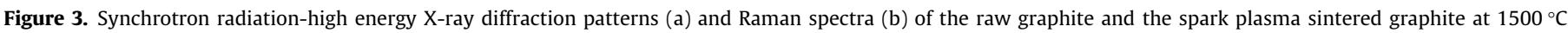
$80 \mathrm{MPa}$ for $20 \mathrm{~min}$.

mond peak at $1333 \mathrm{~cm}^{-1}$ and graphite peak at $1558 \mathrm{~cm}^{-1}$, but the C60 peak at $1460 \mathrm{~cm}^{-1}$ disappeared. It is consistent with X-ray diffraction results that the $\mathrm{C} 60$ has completely transformed into diamond and graphite phases after SPS at $1500{ }^{\circ} \mathrm{C}$ under $80 \mathrm{MPa}$ for $20 \mathrm{~min}$.

Figure 3a shows the synchrotron radiation diffraction patterns of the raw graphite and the SPSed graphite at $1500{ }^{\circ} \mathrm{C}, 80 \mathrm{MPa}$ for $20 \mathrm{~min}$. The raw graphite sample presents Graphite-3R and Graphite-2H diffraction peaks those are centered at $3.348 \AA$ [G3R(0 03 )], $1.674 \AA$ [G-3R( 006$)$ ], $1.228 \AA$ [G-3R(1 10$)$ ] (ICDD No. 26-1079), and $2.138 \AA$ [G-2H(1 00$)$ ], $2.039 \AA$ [G-2H(1 011$)], 1.16 \AA$ [G-2H(1 12$)$ ] (ICDD No. 41-1487). However, it didn't find the diamond phase in the graphite samples after the SPS processing. It only shows an increased intensity in the graphite peaks indicating the improved crystallinity. Figure $3 \mathrm{~b}$ shows the Raman spectra of the raw graphite and the SPSed graphite. The raw graphite shows a sharp peak at $1579 \mathrm{~cm}^{-1}$, and a weak peak at $1350 \mathrm{~cm}^{-1}$. After
SPS processing, the intensity of the peak at $1350 \mathrm{~cm}^{-1}$ has improved, but there is no diamond peak in the Raman spectra. The X-ray diffraction and Raman spectroscopy results confirmed that there is no diamond conversion from pure graphite after SPS at $1500{ }^{\circ} \mathrm{C}$ under $80 \mathrm{MPa}$ for $20 \mathrm{~min}$.

Figure 4a shows the synchrotron radiation-in situ X-ray diffraction patterns of the pure MWCNTs at $80 \mathrm{MPa}$ under different temperatures. The combining peak of MWCNT and graphite has shifted to lower energy values. It indicates the thermal expansion of the nanotubes and graphite planes with the increase of temperature. The boron nitride (BN) peaks are from the container of the powder sample during the in situ high temperature X-ray experiments. However, there is no diamond formation at or below temperature of $1500{ }^{\circ} \mathrm{C}$ under $80 \mathrm{MPa}$. It means that the MWCNTs are dynamically stable at this $1500{ }^{\circ} \mathrm{C}$ temperature under $80 \mathrm{MPa}$ in a nonoxygen atmosphere during the AC sintering. Figure 4b shows the synchrotron radiation-in situ X-ray diffraction patterns of the pure 

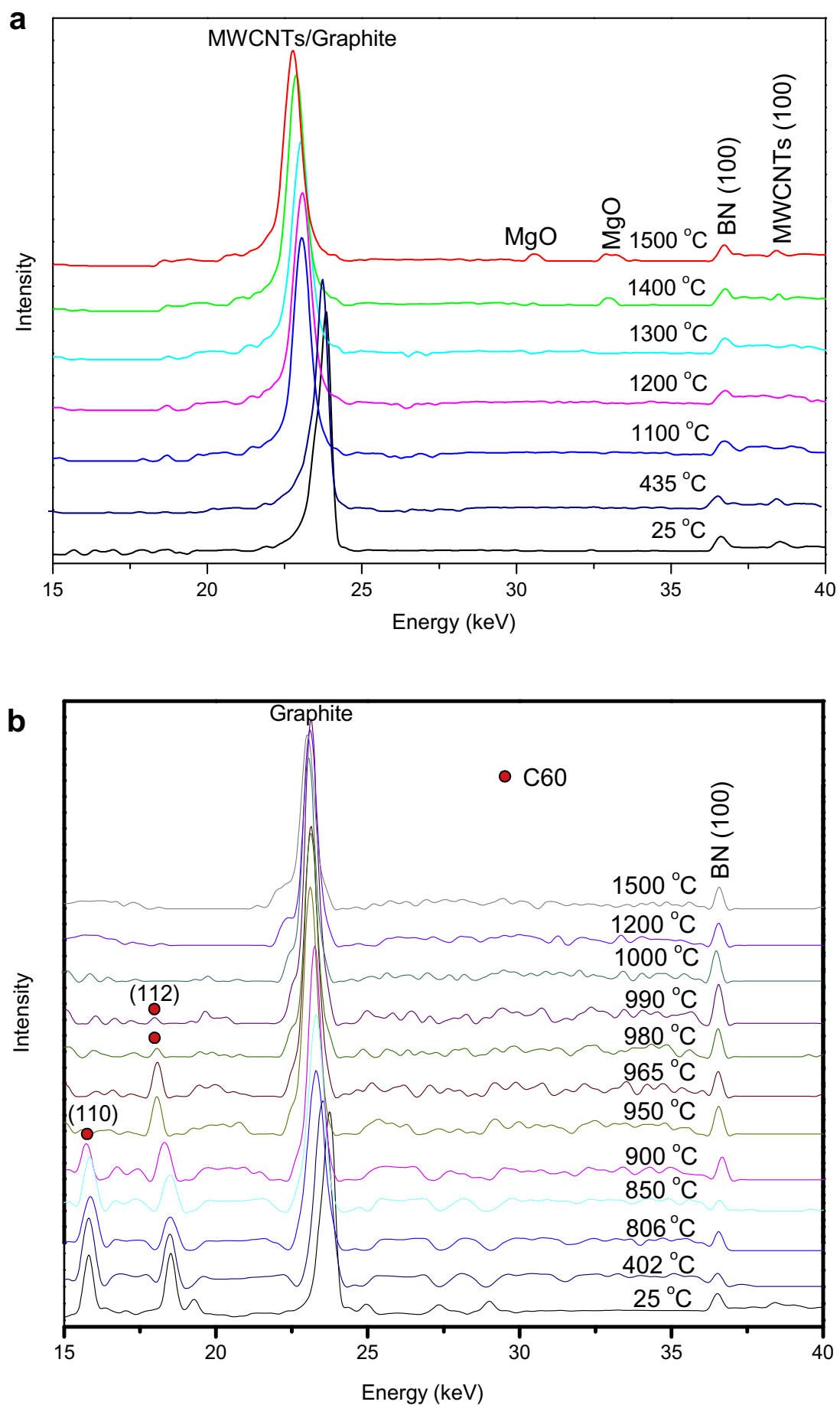

Figure 4. Synchrotron radiation-in situ X-ray diffraction patterns of the pure MWCNTs (a) and C60 (b) at 80 MPa under different temperatures.

C60 at $80 \mathrm{MPa}$ under different temperatures. There is no diamond formation in the $\mathrm{C} 60$ sample. It shows that the $\mathrm{C} 60$ is stable below temperature of $900{ }^{\circ} \mathrm{C}$. However, the C60 is unstable above that temperature point. The $\mathrm{C} 60$ ( 1110$)$ peak disappeared above temperature of $900{ }^{\circ} \mathrm{C}$ and $\mathrm{C} 60$ (1 112 2) peak disappeared above temperature of $990^{\circ} \mathrm{C}$. It is found that the graphite is very stable in the in situ high temperature X-ray experiments at or below temperature of $1500{ }^{\circ} \mathrm{C}$ under $80 \mathrm{MPa}$.

Synchrotron radiation-high energy X-ray diffraction [13] was used to identify the diamond phase in the carbon samples after SPS. In order to confirm the diamond formation, Raman spectros- copy was also used to identify the formation of $\mathrm{sp}^{3}$ bonded diamonds. By using the high energy X-ray diffraction and Raman spectroscopy, the cubic diamond phases were identified and confirmed in the SPSed MWCNTs and C60 samples. The n-diamond was also found in the SPSed MWCNTs sample. The $n$-diamond is a new kind of carbon allotrope, which was a metallic form of carbon with face-centred cubic structure [14]. It is a metastable and intermediate phase, can decompose slowly at room temperature, and has been synthesized accidentally by various processes [15]. This is noted that the $n$-diamond can also be synthesized by the SPS process. The standard d spacing of the cubic diamond (1 111 ), 
(2 2 0) and ( 311 1) planes are centered at 2.059, 1.261 and $1.075 \AA$ (ICDD No. 65-537). The cubic diamond in the SPSed MWCNTs centered at 2.05, 1.23 and $1.06 \AA$, and in the SPSed C60 appeared at 2.06 and $1.23 \AA$ spacing. The diffraction peaks of the synthesized diamond from MWCNTs and C60 are very close to the standard diamond diffraction data, but there is a little shift. The diamond peak shifts are due to the existence of residual stress in the synthesized diamonds from MWCNTs and C60 by using the SPS. The residual stress of the diamond is because of the stress that remains after the original cause of the stresses (uniaxial forces, heat gradient) has been removed after the SPS processing. In this study, uniaxial force of $80 \mathrm{MPa}$ was applied and there generally existed some temperature gradients during the operation of the SPS. Therefore, the diamond peaks in the SPSed MWCNTs and C60 have shifted a little. Combining the results of the Raman spectroscopy, the formation of diamond phases in these MWCNTs and C60 samples is confirmed. It is found that there are no C60 peaks in the X-ray diffraction and Raman results of the SPSed C60 sample, but there are strong unreacted MWCNTs peaks in the SPSed MWCNTs sample, and there are no diamond phases in the SPSed graphite sample. There exists a high activation barrier from the graphite, MWCNTs and $\mathrm{C60}$ to diamond, the exact height of which is unknown. The results in this study indicated that the activation barrier between the C60 and diamond is lower than that of the MWCNTs with diamond, and this barrier between MWCNTs and diamond is lower than that of the graphite with diamond. The graphite is the most stable crystalline modification of carbon among the MWCNTs, C60 and graphite allotropes under the SPS processing.

The SPS is a remarkable technique to synthesize and consolidate a large variety of materials. The process typically uses moderate uniaxial pressures usually below $100 \mathrm{MPa}$ in combination with a pulsing ON-OFF DC current during its operation. There are many mechanisms proposed to account for the enhanced sintering abilities of the SPS process; for example, field assisted diffusion [15], spark impact pressure $[15,16]$, plasma cleaning of particle surfaces [17], Joule's heating [16,17], local melting and evaporation especially in metallic systems [16], surface activation on particles [18] and electron wind force [19]. The one that draws the most controversy of these mechanisms involves the presence of momentary plasma. In this study, the diamond converted from the MWCNTs and C60 without any catalysts being involved in the SPS. However, the parallel investigations by using the synchrotron radiation in situ high temperature X-ray diffraction show that there is no diamond formation in the MWCNTs and C60 samples in the AC sintering at the same pressure ( $80 \mathrm{MPa})$ and temperature $\left(1500{ }^{\circ} \mathrm{C}\right)$. What is their phase transitional mechanism from MWCNTs and C60 to diamond in the SPS? Such a clear, significant difference in the products is due to the special sintering principle of SPS. It is a field activated sintering technique based on an DC electric spark discharge phenomenon, i.e. a high energy and low voltage spark pulse DC momentarily generates sparking plasma between particles, which causes localized high temperatures. It is an electric AC heating in the in situ high temperature experiments. Without plasma effect, it would need $8000-10,000{ }^{\circ} \mathrm{C}$ at pressure of $80 \mathrm{MPa}$ to get diamond from the MWCNTs and C60, as we calculated. Therefore, super-high pressure $(5-10 \mathrm{GPa})$ are required for the diamond formation in the hydrostatic HPHT technique. Since the SPS only needs MPa level pressure, it is believed that the plasma plays the key role for the diamond transformation from the MWCNTs and C60. The high current, low voltage, momentary pulsed plasma discharge have generated highly localized Joule's heating up to a few thousand degrees Celsius between particles in few minutes. The current density in the SPS is typically on the order of $10^{2} \mathrm{~A} / \mathrm{cm}^{2}$ and is highly concentrated at the inter-granular contact or interface [12]. The momentary pulsed plasma provided energy equivalent to thousand degrees to help the nano-carbon across their activation barriers to the diamond phase. It leads to the transformation of mainly $\mathrm{sp}^{2}$ bonded MWCNTs and $\mathrm{C60}$ to $\mathrm{sp}^{3}$ bonded diamonds. Despite the on-going argument about whether the spark plasmas actually occur during the SPS process, our present study, regarding on the generating diamond under such a low pressure, suggests that such spark plasmas indeed took place during SPS of these nano-carbon materials with excellent electrical conductivities and high surface areas. The plasmas generated very high localized temperatures up to about $8000-10,000{ }^{\circ} \mathrm{C}$ and dramatically reduced the pressures required for diamond formation from the GPa to the MPa level. Eventually, this research provided some new indirect evidences for the presence of plasmas during the SPS operation.

\section{Conclusions}

The thermal stability of MWCNTs, C60 and graphite has been investigated under the pulsed DC field in a SPS furnace. Cubic diamond and $n$-diamond have been converted from pure MWCNTs, cubic diamond has been converted from pure C60 without catalysts being involved by the SPS at conditions of $1500{ }^{\circ} \mathrm{C}, 80 \mathrm{MPa}$ for $20 \mathrm{~min}$. There was no notice of diamond formation in the case of pure graphite sample processed by SPS at this condition. The graphite is the most stable crystalline modification of carbon among the MWCNTs, C60 and graphite allotropes under the SPS. The parallel investigations by using the synchrotron radiation in situ high temperature (AC field) X-ray diffraction show that there is no diamond formation in the MWCNTs and C60 samples at the same pressure $(80 \mathrm{MPa})$ and temperature $\left(1500^{\circ} \mathrm{C}\right)$. Their phase transitional mechanism from MWCNTs and C60 to diamond indicated the high localized temperatures between particles due to the presence of momentary plasmas during the SPS process.

\section{Acknowledgements}

This research was supported by the DFG-Deutschen Forschungsgemeinschaft (German Research Foundation) with Grant No. BU 547/10-1 and DESY Hasylab Project with Grant No. II-20090264.

\section{References}

[1] K.M. Liew, C.H. Wong, X.Q. He, M.J. Tan, Phys. Rev. B 71 (2005) 075424

[2] Y.A. Kim, H. Muramatsu, T. Hayashi, M. Endo, M. Terrones, M.S. Dresselhaus, Chem. Phys. Lett. 398 (2004) 87.

[3] Z.A. Munir, U. Anselmi-Tamburini, J. Mater. Sci. 41 (2006) 763.

[4] J.R. Groza, A. Zavaliangos, Mater. Sci. Eng., A 287 (2000) 171.

[5] F. Zhang, J. Shen, J. Sun, Y.Q. Zhu, G. Wang, G. McCartney, Carbon 43 (2005) 1254.

[6] J. Shen, F.M. Zhang, J.F. Sun, Y.Q. Zhu, G. McCartney, Nanotechnology 17 (2006) 2187.

[7] F. Zhang, J. Shen, J. Sun, D.G. McCartney, Carbon 44 (2006) 3136.

[8] F. Inam, H. Yan, M.J. Reece, T. Peijs, Adv. Appl. Ceram. 109 (2010) 240.

[9] U. Anselmi-Tamburini, S. Gennari, J.E. Garay, Z.A. Munir, Mater. Sci. Eng., A 394 (2005) 139.

[10] D.M. Hulbert et al., J. Appl. Phys. 104 (2008) 033305.

[11] R.J. Hemley, G.L. Chiarotti (Eds.), High Pressure Phenomena, IOS Press, Amsterdam, 2002.

[12] K. Yang, J. He, Z. Su, J.B. Reppert, M.J. Skove, T.M. Tritt, A.M. Rao, Carbon 48 (2010) 756.

[13] E. Burkel, J. Phys. Condens. Matter 13 (2001) 7477.

[14] B. Wen et al., J. Phys. Condens. Matter 16 (2004) 2991.

[15] G.D. Zhan, J. Kuntz, J. Wan, J. Garay, A.K. Mukherjee, J. Am. Ceram. Soc. 86 (2003) 200.

[16] M. Omori, Mater. Sci. Eng., A 287 (2000) 183.

[17] W. Chen, U. Anselmi-Tamburini, J.E. Garay, J.R. Groza, Z.A. Munir, Mater. Sci. Eng., A 394 (2005) 132.

[18] N. Frage, S. Cohen, S. Meir, S. Kalabukhov, M. Dariel, J. Mater. Sci. 42 (2007) 3273.

[19] P. Shewmon, Diffusion in Solids, second ed., Minerals Metals \& Materials Society, Warrendale, PA, 1989. pp. 246. 